\title{
Pro mundo ficar Odara: Não entender Exu
}

\author{
Alexandre de Oliveira Fernandes \\ Doutor em Ciência da Literatura
}

Àgò, Exu àgò ${ }^{1}$

A única decisão possível passa pela loucura do indecidível e do impossível: ir aonde é impossível ir.

Jacques Derrida

Conversar é dar voltas no pensamento, teria afirmado Humberto Maturana. Tais voltas não seguem uma lógica cartesiana e uma medida positiva como se poderia pensar inicialmente, mas estão repletas de sobressaltos, idas e vindas, fatos intervenientes, colapsados pela agonia da metáfora, da poesia e da tradução.

O que é uma conversa afinal, senão jogos de interpretação? Mobilizada por desejos íntimos, fermentada nas pulsões e manietada pelo inconsciente, aquecida no caldeirão do que há em nós de mais subjetivo e passional, a conversa se distancia do diálogo socrático-platônico. Aqueles senhores gregos, sabichões, tão escovadinhos e corretos não se sustentariam em uma conversa real com gente de verdade. Gente é afetada, transpira afeto e emoção. Gente é algo da ordem do trágico-nietzschiano, em que a vida transborda, cheia de sabores, músicas e contendas entre Dionísio e Apolo, ação e reação, construção e desconstrução.

A psicanálise, uma conversa com o inconsciente, perguntava sob a voz de Jacques Lacan: “O que você quer? O que realmente quer?” Carl Gustav Jung queria saber de seus pacientes: “Que mito está vivendo hoje?” Estas questões não solicitam respostas conclusivas, não encerram nada, sacodem certezas e colocam a resposta para deslizar numa agonia sem fim.

\footnotetext{
${ }^{1}$ Àgò é reverência, pedido de compreensão, licença e desculpas (LOPES, 2004, p.40).
} 
Ana O., paciente de Sigmund Freud, queria simplesmente falar, e que não a interrompessem. Ana O. estava conversando consigo mesma e limpando sua chaminé, deslizando na agonia do sem fim. Dizendo, dizia de si e dos outros. Catava-se. Buscava juntar-se, compreender, sabendo que não há lugar de placidez no entendimento. $\mathrm{O}$ entender não liberta, aprisiona.

Como Narciso, Ana O. olhava para si no espelho d'água da conversa. O espelho, tal qual uma conversa, é a possibilidade de se desprender de si. Quando me olho no espelho, não é para mim que olho, mas para um outro, um reflexo, um eu suposto.

Um eu ex-posto, fora de posto surge no espelho da conversa que provoca desconforto. Sou um eu refletido e não o sou ao mesmo tempo. Aquele a me olhar no espelho, quem é? É um ambíguo.

Mas, claro, sempre se corre o risco de crer que o espelhado indica a mim mesmo, que retoma a mim mesmo. Este fio da navalha pode implicar em um ego autocentrado, como também na possibilidade de (se) ver na diferença semelhante.

O que se (ex)trai em uma conversa? Retratos subjetivos e autênticos. Estruturados numa sintaxe construída por um "eu” ilusoriamente autêntico, um "eu" paranoico - porque todos somos essencialmente paranoicos, os retratos do "eu" nunca dizem dele em completude, são flashes, recortes, compostos por uma conversa, subversiva e poderosa tanto quanto mais estiver aberta à paranoia.

Na conversa paranoica desponta a realidade imediata que se faz presente para o sujeito; ele a vive mesmo que esta seja “irreal”. É o que sente, deprime, motiva, o que lhe dá medo e impulsiona, é o que seduz.

Como resultado de minhas paranoias, gostaria de conversar (e "jogar" conversa fora) sobre (e com) Exu. Destaco "uma” dentre as várias conversas possíveis que por aí circulam e das quais poderia me apropriar. E reparem que se alguém/algo circula nesta vida de meu Deus, este é Exu, o senhor do movimento. Um corpo sem Exu é um corpo em coma, já afirmou o NATA². Puxo um ponto da/de conversa, sem preocupação, porque a conversa "já" começou e o fio já fora puxado - mas onde e quando? E se digo que puxo um ponto é apenas para parecer

\footnotetext{
2 Núcleo Afrobrasileiro de Teatro de Alagoinhas.
} 
didático e nada mais, porque, ora, uma certeza entre dez escolhas é que se perderam nove. Tomo o turno da fala e relembro-lhes o documentário "Exu: Além do Bem e do Mal3", dirigido por Werner Salles Bagetti.

As conversas exurianas presentes nos pouco mais de 23 minutos de "Exu: Além do Bem e do Mal” trazem vozes da umbanda, candomblés, juremas, "especialistas" (de babalorixás a antropólogos), os quais cotidianamente conversam e cantam (em português, em iorubá) sobre Exu e inventam-no.

Cada qual inventa seu Exu, Legba, Aluvaiá, Legbara, Bará, Eleguá, Trancarua, diabo, capeta. Estou dizendo "inventam" porque não há um significado fixo e unívoco de Exu que seja transportado de uma "fala" para outra como se este fosse um pacote, um embrulho. Cada Exu é artefato de invenção, resultado de conversas e diálogos, entrecortado, selecionado. E haja polifonia nas vozes que enunciam Exu. E no trânsito das conversas que vão e vem.

Arrastado por conversas, materializado por discursos que lhe atravessam o corpo e o constroem na diferença, no contato e na alteridade, tanto a diáspora negra quanto a colonização europeia e católica do continente africano falam de Exu, deus da sexualidade, frequentemente "confundido" com o diabo cristão.

Quem conta um conto aumenta um ponto, sim? Neste aspecto, cada Exu é um invento, mas também é um produto "único", exatamente porque, aquele que “conversa” acaba por "traduzir" - em palavras, imagens, músicas, danças, artes plásticas, fotografias, contos - seu Exu.

O documentário de Bagetti conversa com Exu, abre espaço para que fale, dialogue, dance, incorpore, responda e pergunte. Faz dialogar todo um universo simbólico, polifônico e controverso em que o Deus do Falo é produzido.

Deus do bem e do mal, para além do bem e do mal, faz o que lhe pedem, ri de tudo e de todos, é uma personagem não definida. Controverso, toma o corpo de seus iniciados, toma corpo com os seus iniciados, desce neles e faz emergir, no transe, as transas e os trânsitos mais recônditos de cada um, “o universo primevo do homem, momentos antes da descoberta do estigma do pecado original” ${ }^{4}$. Coloca

\footnotetext{
${ }^{3}$ Cf. https://vimeo.com/51492394.

${ }^{4}$ Cf. Mario Cravo Junior, “A Bahia negra: o paraíso sempre desejado”, texto sobre exposição de Mário Cravo. Disponível em http://www.cravoneto.com.br/dahomey/port/pag04.htm.
} 
a nu os desejos, as demandas, na base de gritos, gargalhadas, baforadas de charutos e danças lascivas.

Bagetti se põe a contar um mito em que Exu era um vagabundo. Ao ter contato com Oxalá, trabalhando com ele, carregando os ebós torna-se rico e poderoso. Torna-se o senhor das encruzilhadas, a base do sistema nagô, o elo, o caminho que liga, o religare em si, a própria religião. Apenas sobre este mito há tanto o que conversar. Tantos Exus saltam deste conto...

Cada posicionamento, que nunca é um só, nem de si para si, nem transparente porque não está sozinho no mundo como se fosse um heterogêneo, fixo e auto evidente, constrói "seu" significado na "sua” língua, imagina-o, modelao, sob "suas" perspectivas e interesses, e o lança como num jogo de conversas - Exu baixa na umbanda, mas não baixa no candomblé -, linguagens e interpretações de interpretações em que cada conversador, herdeiro desse Exu, põem-no em movimento não-finito de proliferações e disseminações - Exu baixa na umbanda e baixa no candomblé, na nação jejê, angola e ketu, tudo dependendo sempre de quem é o conversador da vez -, lançando um Exu a outro Exu, que como um grito sobe ao Orun e escorre pelas encruzilhadas das veias de cada um de nós.

Pergunta Bagetti, o que é Exu então? Como atua? Qual sua função? Onde pode ser encontrado? "Em todo o canto", diz "Exu Rei". Este lhe responde incorporado em uma mulher, fumando charuto, descalço e usando chapéu grande, camisa de algodão e calça pantalonada. "Exu Rei” em corpo de mulher: é homem ou é mulher? Ele mesmo parece responder: "Existe o bem sem o mal? O bom sem o ruim?" Existe homem sem mulher? Nem Exu sem Pomba-gira.

Exu é o mensageiro - de uma carta roubada, porque a mensagem nunca chega em sua inteireza e estabilidade -, "serve" aos orixás, é um contexto e uma perspectiva, um movimento, uma performance, uma sequência não linear ou lógico causal de atos, cenas, cortes, seleções e inscrições em que ritos e mitos ganham vida, aqui e agora, com toda sua carga simbólica.

Exu é uma conversa complexa que dá voltas no pensamento. É fala, eloquência, conversa, a própria comunicação. Não havendo qualquer necessidade de algum atrevido tentar se apropriar de um Exu que lhe seja "o" original, o 
verdadeiro. Quem é capaz de contê-lo? Como traduzi-lo senão sob a capa da cultura e do colonialismo?

(...) se escolho a palavra Kami, que teoricamente deveria ser traduzida por deus ou espírito, eu adapto, na verdade a palavra Kami à nossa cultura. Se tentar realmente defini-la, precisaríamos de muitas páginas para fazê-lo e precisaríamos ainda recorrer a vários graus e níveis de conhecimento. Por isso nunca nenhum japonês se arriscou a explicá-la (Random, 2002, p. 42).

Exu está mais para o mito do que para a lógica. Exu é mito-morfo e não mito-lógico. Por que explica-lo então? O mito se aproxima da arte, enquanto a racionalidade se ampara na "verdade" tecnocientífica que sustenta a vida moderna, ressaltando sobre que espécie de suposições e modos de pensamento habituais, incontestados e despercebidos, se assentam as práticas naturalizadas. Tais práticas se sustentam por meio de páginas e páginas de leis e normas - tão longas no tempo e no espaço que somos levados a esquecer de seu caráter de ficção -, sistemas e dispositivos de controle que reiteram cotidianamente suas normas e regras.

Mas, Exu é pré-socrático, helênico, nietzschiano. Sua sensibilidade é pósmoderna. Tem a ver com a atomização dos objetos e dos pontos de vista; a identidade movente, o interesse pelas diferenças e pelos excluídos; a história como constructo discursivo; a noção da complexidade e a consequente dissolução de fronteiras entre as disciplinas; o questionamento sobre a autoria dos textos literários, a intertextualidade; a instabilidade da estrutura da narrativa; as relativizações do processo de significação da realidade; o descentramento; a imprevisibilidade do sentido.

Exu é um incerto, dando lugar a perguntas que "dançam”, "rodopiam" na cabeça das pessoas. Exu não pode ser entendido nele mesmo. Isso iria de encontro à intertextualidade, à polifonia, à disseminação. Nos mitos, Exu precisa de Oxum, tanto quanto Obatála precisa de ambos. E não é assim nos textos gregos? Teseu 
precisa de Ariadne para voltar do labirinto após matar o Minotauro. Do que ao fim e ao cabo, tratam estas histórias? De fios da existência humana, entrelaçados, cuja extensão e exposição de novelos, levam-nos, dentre outras possibilidades, sempre estendendo o fio, a conversas com Exu. Mas com qual?

Quem se atreve a deter um Exu original, bem marcado e verdadeiro, ou bem é um ingênuo desavisado ou um proto-fascista fundamentalista. Tanto um quanto o outro deveriam abrir-se ao diálogo. De ambos tenho medo: do ingênuo (que não despertou para a maioridade kantiana) e do fundamentalista (que não compreende que o amor só ocorre na diferença e na hospitalidade absoluta derridiana).

Uma conversa descrita por Umberto Eco denota que os originais (e toda a clausura essencialista da Metafísica) não resistem a um olhar mais apurado. Os originais são cópias de cópias. Reparemos na conversa:

- Agora mostro aos senhores aquele texto. Consintam que lhes mostre uma fotocópia. Não por desconfiança. Mas para não submeter o original a manuseio.

- Mas o documento de Ingolf já não era o original, disse eu. Era a cópia que ele fizera de um suposto original.

- Sr. Casaubon, quando os originais já não existem, a última cópia passa a ser o original.

- Mas Ingolf podia ter transcrito mal.

- O senhor não sabe se é assim. E eu sei que a transcrição de Ingolf diz a verdade, porque não vejo como a verdade poderia ser outra. Portanto, a cópia de Ingolf é o original. Estamos de acordo nesse ponto, ou vamos ficar fazendo brincadeirinhas intelectuais? (ECO, 2009, p. 143).

No diálogo temos um paradoxo: a cópia é o original. Temos também um alerta: o copista pode ter transcrito mal. A desconstrução do original implica em que só haja cópias de cópias. Não há o original, a essência, o numero “um”, porque no processo de linguagem, transferência de sentido, mudança de turno, uso de 
metáforas e metonímias, somos sempre copistas que tentam dizer algo acerca de um suposto original - ao qual nunca se tem acesso. Somos falhos por excelência porque nossa linguagem cansa e não alcança.

Mas, podemos nos abrir a uma "racionalidade verdadeira" - estou me apropriando de Edgar Morin (2011) e a "brincadeirinhas intelectuais”. Reparemos no "Exu Malandro" falando de si no documentário de Bagetti: "Entenda cada um o que tiver que entender. Eu não tô aqui pra explicar”.

E o "Malandro" inverte o jogo: “Da mesma forma que vocês tão fazendo esse documentário pra tentar entender eu, eu tô tentando entender vocês agora”. E diz, "eu não faço mais parte desse mundo".

Multifacetado está neste mundo, incorporado em alguém que conversa conosco, toma vinho, cerveja, cachaça, fuma charutos e cigarros, mas, paradoxalmente, não está neste mundo porque já morreu e estaria em outro plano que não este.

As "brincadeirinhas intelectuais" dos malandros, sejam os do Terreiro ou os da Academia, colocam sob suspeita e em suspenso o pensamento binário e hierárquico. Como procedem? Numa malemolência própria da troca de ideias, opera-se um vaivém entre a lógica clássica e o empírico, sem ignorar os seres, a subjetividade, a afetividade.

O que salta desta volta no pensamento? A Vida, com nossos desejos, afecções e paranoias. Saltam os mitos, os afetos, os amores, os escárnios, os arrependimentos, o luto e a melancolia.

Se levados a serio dentro de uma racionalidade que conhece os limites da lógica, do determinismo e do mecanicismo, os mitos põem a vacilar o imperativo da verdade e a arrogância do espírito humano que se entende como onisciente. A onisciência e a prepotência ignoram a necessária humildade diante do mistério tremendo e fascinante que é a Vida, podendo ser, inclusive, instrumentos de redução da realidade, num posicionamento que domestica o pensamento.

Há alguma novidade no fato de que a depender do modo como nos posicionamos em um diálogo, percebemos coisas diferentes? A partir do lugar que ocupamos também. Ora, do planeta terra pode-se ver a Lua "nascer" no horizonte. 
Estando na Lua, os astronautas da Apolo 11 viram o "nascer da Terra". No Brasil, o pastor Silas Malafaia vocifera contra direitos civis gays, enquanto outro líder evangélico, Marcos Botelho5 , vê a situação por ângulo diverso:

Hoje, vendo a luta do movimento LGBTT, lendo a PL 122 e pensando no nosso compromisso cristão por uma sociedade para todos com as leis laicas, penso que o direito ao casamento (união estável), a herança e outros direitos civis dos homossexuais deveriam ser garantidos por lei e defendidos por nós protestantes, pois se sofremos um preconceito no passado por leis baseadas na fé dos 'outros' que iam contra os nossos direitos, por que agora que temos voz garantida não vamos lutar pelos outros?... Nós evangélicos deveríamos ser a voz em defesa (dos direitos legais) dos homossexuais...

É verdade que a Igreja Católica não permite o aborto, mas, esta decisão é majoritária? A conversa estaria encerrada? Não. Os interesses das "Católicas pelo direito de decidir ${ }^{6 "}$ tem empurrado o debate e dado voltas no pensamento. O papa Francisco demonstra ser mais acolhedor com casais separados e sujeitos homoafetivos, apesar de o "Sínodo dos Bispos sobre a família" excluir temas como a homossexualidade e o acesso à comunhão para os divorciados que tornam a se casar.

Em texto intitulado “Deus é negro", Frei Betto afirmou ser filho de Ogum e Oxalá. Católico e filho de orixá, compartilhando-se e compartilhado por dois sistemas religiosos, temos um frei que une o catolicismo e o candomblé em seu corpo por meio de uma visão complementar não dualista:

\footnotetext{
${ }^{5}$ Cf. http://ultimato.com.br/sites/marcosbotelho.

${ }^{6} \mathrm{Cf}$. http://www.catolicasonline.org.br/.
} 
Ferve em meu sangue uma África. Sou filho de Ogum e Oxalá, devoto de Iemanjá, a quem elevo as oferendas de todas as dores e cores, lágrimas e sabores, o choro inconsolável das senzalas, a carne lanhada de cordas, os pulsos e os tornozelos a ferros, a solidão da raça, o ventre rasgado e engravidado pela feroz pulsão dos senhores da Casa Grande (FREI BETTO, 2004, p. 105).

Ao invés de separações "didáticas" e grosseiras, com suas caricaturas desqualificadas do saber, impõem-se a impertinência, o devir e a consciência de que o que se sabe é infinitamente pouco, mas que se deve caminhar para um conhecimento responsável, ético, humanista, um conhecimento prudente para uma vida decente, compartilhada e Odara.

Deixa eu conversar que é pro mundo ficar Odara, afirmo. A meu modo, há algum tempo venho me lançando em uma conversa com Exu. Não me interesso por desvelar, revelar, mas, por meio de um jogo erótico e sedutor (produzido num entre-lugar da Academia e dos terreiros), colocar o sentido para dançar e fazer o pensamento se movimentar lascivo e aporético, como se jogasse capoeira - com suas esquivas e golpes -, como se estivesse em êxtase religioso ou simplesmente, como quem joga conversa fora numa roda de amigos, preferencialmente regada a uma boa caninha.

Exu Odara expõe uma agonia no interior dos sistemas que produzem sentidos sobre Exu. Sem nunca poder defini-lo(s) senão sob a capa perigosa de um contexto e de uma perspectiva, Exu responde às interpelações e às interpretações que buscam lhe cavar um lugar, ora como o bem, ora como o mal, como o deus da ordem, como o signo do caos, como o malandro das gafieiras, como a pomba gira das encruzilhadas e a puta que pede passagem.

Pois bem, converso com Exu e lhe digo: "Exu, eu não consigo entender Exu”. $\mathrm{Na}$ Universidade tentamos apreender o discurso por meio da razão e da crítica, do passar em revista as teorias e os discursos do intelecto. Mas, talvez, os terreiros que cotidianamente evocam o Dono do Falo, aproximem-se mais rapidamente do deus 
da ordem e do caos, tanto quanto - e de modo surpreendente - estejam mais próximos de Jacques Lacan que conversa com Daniel Lins, seu aluno.

Daniel Lins, sociólogo, filósofo e psicanalista, quando era aluno do francês Jacques Lacan pretendeu desistir de suas aulas porque não as estava entendendo. A questão se daria da seguinte forma: ou bem ele, Daniel Lins era uma burro ou Lacan seria um monstro da inteligência. Era o que pensava Lins. Este procura o mestre e lhe diz: "Lacan, eu não consigo entender Lacan”. O professor responde com humildade: "Muitas vezes eu também não consigo entender Lacan”. A proposta então era muito mais sentir do que entender ${ }^{7}$. Entender Lacan não era da ordem da síntese explicativo-dialética, mas daquilo que vaza, desliza, escorrega e se abre à clivagem do ambíguo.

Conversar com Exu é colocar em jogo a episteme. O que está em questão é o conhecimento, a epistemologia, a relação saber - poder, que possibilita amplitude tanto quanto pode se nos cegar.

Conformada, a epistemologia leva à redução da realidade, à aceitação do que já existe e nos acomoda ao dado-dado, a uma concepção conservadora de cultura, sem comprometimento com o papel social implícito ao conhecimento. Tecnicista e conservadora, uma epistemologia que não leve o sentir a sério (assim como o diálogo, as conversas, o diálogo com Exu, pois, no dia-a-dia, os textos míticos são percebidos muito mais pelos sentidos, pelo sensível, por sua ligação com a realidade direta e cotidiana de cada indivíduo do que pela chamada ciência), reproduz as estruturas, reflete a posição dominante, confundindo-se com uma onto-teo-logia, ou seja, com um esquematismo da presença, assentado na metafisica desde os gregos e com maior ênfase, fortalecido pelo cristianismo.

A metafísica e a ciência tem tornado o mundo e o Ser num objeto em que a técnica, como um conjunto de receitas, se impõe à existência, ao mesmo tempo em que, tem dificuldades em compreender a complexidade da natureza, a saber, a dualidade da matéria e da luz, em que, a depender do modo como observamos, ora se nos aparecem como ondas, ora como partículas.

\footnotetext{
${ }^{7}$ Cf. https://www.youtube.com/watch?v=1saZGzLM1Vk.
} 
Ainda conversando, Exu se nos apareceria como ondas ou partículas? Eis o eterno retorno da pergunta e do diálogo que não se resolve em uma síntese hegeliana, esta sendo capaz de agredir sistemas de saberes tradicionais que não se reduzem aos jogos de opostos verdadeiro/falso. Uma episteme exuriana é capaz de dar conta da historia universal para além da historia ocidental, fundada numa dialética não simplista, num pensamento para a alteridade e para a desmercantilização da vida e a descolonização do pensamento.

Daí o deboche e a crítica de Exu em "Além do bem e do Mal": "E para aqueles que não acreditam em eu, que se danem! Você tá fazendo isso pra quem acredita não é? Quem não quiser acreditar (e balança a cabeça negativamente)... eu não tô preocupado, sabe por quê? Não vou morrer de novo...” Acende seu cigarro e ri, o gaiato.

Gaiatice que encontro também em Jacques Lacan: uma análise não deve ser forçada a ir muito longe, quando o analisado pensa em estar feliz da vida, é o bastante. Por que prosseguir? Eu, pelo menos, estou feliz.

Referências

BETTO, Frei. Típicos tipos. São Paulo: A Girafa Editora, 2004.

ECO, Umberto. O pêndulo de Foucault. Tradução: Ivo Barroso. Rio de Janeiro: BestBolso, 2009.

FERNANDES, Alexandre de Oliveira. Axé: Apontamento para uma a-tese sobre Exu que jamais (se) escreverá. Rio de Janeiro: UFRJ, 2015.

MORIN, Edgar. Rumo ao abismo?:ensaio sobre o destino da humanidade. Tradução: Edgard de Assis Carvalho e Mariza Perassi Bosco. Rio de Janeiro: Bertrand Brasil, 2011.

RANDOM, Michel. O território do olhar. In: Educação e transdisciplinaridade II. São Paulo: TRIOM, 2002. 